\title{
A Confirmatory Factor Analysis of the Motivated Self-regulated Learning Questionnaire in an EFL Context
}

\author{
Mohammad Ali Ayatollahi (Corresponding Author) \\ Faculty of Foreign Languages, University of Isfahan \\ Faculty of Foreign Languages, University of Isfahan, Isfahan, Iran \\ Tel: 98-711-630-6518 E-mail: ayat_ma2001@yahoo.com
}

\begin{abstract}
Abbas Eslami Rasekh
Faculty of Foreign Languages, University of Isfahan

Faculty of Foreign Languages, University of Isfahan, Isfahan, Iran

Tel: 98-913-110-3989Ｅ-mail: abbasseslamirasekh@yahoo.com
\end{abstract}

Mansoor Tavakoli

Faculty of Foreign Languages, University of Isfahan

Faculty of Foreign Languages, University of Isfahan, Isfahan, Iran

Tel: 98-913-225-9957Ｅ-mail: m.tavokoli14@gmail.com

Received: April 29, 2011 Accepted: June 7, $2011 \quad$ Published: November 1, 2011

doi:10.5539/ies.v4n4p230

URL: http://dx.doi.org/10.5539/ies.v4n4p230

\begin{abstract}
The Motivated Strategies for Learning Questionnaire (MSLQ) is an instrument for measuring motivation and learning strategies in general education. This instrument is modular, consisting of motivation and learning strategies modules. This study sought to see whether the learning strategies module of this instrument can be applied to the context of English Language Learning (EFL). For this purpose, the instrument was administered to a group of Iranian EFL college students $(n=190)$ as well as a group of Iranian computer science students $(n=74)$. The validity of the learning strategies module of this instrument in the new context was studied by analyzing the factor structure of responses made to it. Confirmatory factor analysis was run to perform a factor analysis of the data. Confirmatory factor analysis revealed identical factor structures for EFL and general education contexts, suggesting that MSLQ is a valid measurement instrument in determining EFL college students' study strategies as well.
\end{abstract}

Keywords: Self regulated learning, Cognitive strategies, Metacognitive and resource management strategies

\section{Introduction}

Although the most famous language learning strategies instrument i.e., Strategy Inventory for Language Learning (SILL) developed by Oxford (1990) is extensively used by EFL researchers, recently some researchers have become aware of some of its limitations. According to Tseng, Dörnyei, and Dierking (2006) SILL focuses on specific strategic behaviors. Thus, the items there can be considered as behavioral items. This means:

We cannot assume a linear relationship between the individual item scores and the total item scores. For example, one can be a good memory strategy user in general while scoring low on some of the items in the memory scale e.g. acting out a new word or using flash cards. Thus,.... (such) scales are not cumulative and computing mean scale scores are unjustifiable psychometrically (Tseng et. al. 2006, p. 83).

Yet many researchers are interested in carrying out factor analytic research. The factorial nature of such research requires that the instruments employed have two properties. First, they are assumed to tap into an underlying trait. Second, the items in subscales need to be consistent in a way that scoring high in one item in a sub scale needs to be reflected in other items in that subscale as well. Given such considerations, a Self-Regulated Learning (SRL) view is deemed appropriate for investigating the research questions in factor analytic research. 
Viewing learning strategies from the SRL perspective entails a shift of focus. It shifts the focus from the actual strategies and techniques that learners apply to the learners' innate self-regulatory capacity. It is this underlying capacity that motivates learners to apply personal strategic learning mechanisms (Tseng et al., 2006). As a result, instruments developed to measure self-regulated learning strategies such as Motivated Strategies for Learning Questionnaire (MSLQ) are different from the more commonly used measures or inventories of language learner strategies, such as the SILL. Tseng et al. (2006) state that the items in SRL learning strategy instruments "tap into general trends and inclinations and can therefore be assumed to be in a linear relationship with some corresponding underlying learner trait" (p. 83).

\section{Theoretical Framework}

The most commonly used instrument within the framework of self-regulated learning is the Motivated Strategies for Learning Questionnaire (MSLQ) developed by Pintrish, Smith, Garcia, and McKeachie (1991). It is a multi-component Likert-scale questionnaire consisting of two scales, the motivation scale and the learning strategies scale. The questionnaire is designed to measure cognitive study strategies, motivation, and metacognition, all of which fall under the umbrella term of self-regulation (Pintrich, 2000, Schunk and Ertmer, 2000, Winne, 1995). The learning strategy component consists of two subscales: (a) cognitive, and (b) metacognitive and resource management strategies. According to Pintrich, et.al. (1991) the Motivated Strategies for Learning Questionnaire (MSLQ) scales "are designed to be modular and can be used to fit the needs of researchers" (p. 3). The cognitive subscale is comprised of the following components: 1-rehearsal strategies, 2- elaboration strategies, 3- organization strategies, and 4- critical thinking strategies. the metacognitive and resource management component is comprised of: 1- metacognitive self-regulation, 2- time and resource management, 3- effort regulation, and 4- help seeking.

Rehearsal strategies include activities such as underlining, verbalizing the content, and using mnemonics that help readers select and keep information in memory. Such strategies emphasize performance rather than the intellectual mastery of the material. (Warr and Downing, 2000).

In contrast, elaboration strategies are directed at the construction of a situational model of the text. They are in line with a deep approach to learning. They include such strategies as reciprocal teaching, summarizing, and note taking. They are thought to lead to deeper understanding of texts. Such strategies are more concerned with the mastery of the material. Thus, they require learners to examine implications and link the material to be learnt with the existing knowledge (Swalander and Taube, 2007).

Organization strategies are directed at grasping the semantic macrostructure of texts. They include activities such as semantic mapping, highlighting the main ideas, making diagrams and tables that help readers confirm their understanding of the text.

Critical thinking strategies are the most demanding strategies discussed so far. Critical thinking has been defined as "reasonable, reflective thinking that is focused on deciding what to believe or to do" (Ennis, 1991 cited in Ten Dam and Volman, 2004, p. 360). Critical thinkers are normally engaged in "formulating hypotheses, alternative ways of viewing a problem, questions, possible solutions, and plans for investigating something" (Ten Dam and Volman, 2004, p. 360). Critical thinking strategies help readers make sound judgments. They include such activities as deciding whether or not a particular conclusion or interpretation is supported by evidence, trying to develop one's own ideas about the course materials, and thinking about possible alternatives.

The metacognitive and resource management component is comprised of metacognitive self regulation strategies, time management strategies, effort regulation strategies, and help seeking strategies. Metacognitive strategies are to do with planning, monitoring and evaluating. Time management strategies help students to control the time and place of study. Effort regulation strategies are employed by learners to adjust their effort levels to the task. Such decisions as to when to persist and when to stop doing a task are related to this aspect of learning. Help-seeking strategies refer to learners' asking for help from others when they face a problem.

\subsection{Statement of the Problem}

MSLQ has been designed for studies carried out within the framework of general education. However, researchers in the field of second language acquisition (SLA) have recently shown interest in the applicability of this instrument to SLA research. For example, Huang (2008) investigated the reliability of the Motivated Strategies for Learning Questionnaire (MSLQ, Pintrich, et al. 1991) and its correlation with L2 achievement. He found that "in spite of some inherent uniqueness, L2 learning is similar to other subjects in the school environment and the MSLQ has the potential to be applied to L2- related studies" (p. 259). Stoffa, Kush, and Heo (2011) reported similar findings. Furthermore, they tested the possible overlap between MSLQ and Strategy Inventory for Language Learning (SILL) (Oxford, 1990). 
They found "while the two scales do have similar content, the scales do not overlap entirely and appear to measure two discrete indices".

Since learning strategies are sensitive to cultural differences (Tan, 2010), the researchers felt the need to do a similar study in the context of Iranian universities. Thus, in order to test measurement invariability of MSLQ in general education and L2 learning, they administered the instrument to two groups of students, namely, a group of EFL college students and a group of computer science college students.

\subsection{Research Questions}

The main purpose of this study was to investigate the measurement invariance of the learning strategies component of MSLQ questionnaire in EFL context and general education. Thus, it was assumed that this instrument had identical factor structure across EFL and other academic disciplines. Furthermore, it was assumed that the results of factor analysis should conform to the theory of self regulated learning (Zimmerman and Risemberg, 1997). Thus, this study addressed the following research questions.

1- Are there any differences between the factor structure of the learning strategies component of the MSLQ and the theoretical assumptions regarding its structure?

2- Are there any differences between the factor structure of the learning strategies component of the MSLQ when answered by Iranian EFL and computer science students?

\section{Method}

\subsection{Participants}

The participants in this study were 190 Iranian EFL college students and 74 Iranian computer science students. The mean age of the former group was 23.04 for men $(\mathrm{SD}=3.43)$ and 21.91 for women $(\mathrm{SD}=3.21)$. The mean age of the latter group was 22.07 for the male participants $(\mathrm{SD}=2.33)$ and 21.91 for the female participants $(\mathrm{SD}=3.07)$. The sample size is considered to be sufficient given Bentler and Chou's (1987) criteria of 10 to 15 participants per variable for each measurement model. The participants were recruited from Shiraz and Sepidan branches of Islamic Azad University.

\subsection{Procedure}

Motivated Learning Strategies Questionnaire (MLSQ) was introduced to the participants in the study in different sessions. The participants were informed that (a) there were no right and wrong answers in the questionnaires, (b) the instruments were used only to gather information for the purpose of research and they were not linked to any form of classroom evaluation, and (c) the information obtained would be kept confidential.

\subsection{Data Analysis Method}

The researchers used confirmatory factor analysis via AMOS Graphics to evaluate the model fit of MSLQ as a measurement model in two separate contexts i.e., the context of general education and English language teaching (EFL). There are two types of confirmatory factor analysis (CFA): single-group CFA and multi-group CFA. Single-group CFA can be used to test the validity of the a priori expected factor structure on several fit indices (Bentler, 1990). As such, it requires that researchers have substantive theoretical and empirical support for the relationship between the presumed constructs and corresponding indicators (Byrne, 2001). Multi-group confirmatory factor analysis is used to evaluate invariance across groups.

In this study we first used single-group confirmatory factor analysis to evaluate the model fit of the responses given to motivated self regulated learning strategies (MSLQ) by the college students of computer science $(\mathrm{n}=74)$ and English as a foreign language $(E F L)$ students $(n=190)$ separately. Given the acceptable model fit indices in each group, we then proceeded to use multi-group CFA to compare the factor structure of the measurement model between the two groups.

\section{Results}

\subsection{Single Group Factor Analysis}

Table one shows the results of correlation matrix for sample one i.e, EFL students. All correlation coefficients among the categories were significant at $p<0$. 01. The highest correlation $(\mathrm{r}=.84)$ among the categories was between the scores on help seeking strategies and time management strategies. The lowest correlation $(\mathrm{r}=0.58)$ was between the metacognitive strategies and elaboration strategies.

In the next step, single-group confirmatory factor analysis was computed. When this type of analysis is conducted, models are set up for the data and the goodness-of-fit statistics are used to test the hypotheses. Self regulated learning strategies are hypothesized to consist of two latent variables i.e., metacognitive and resource management strategies 
and cognitive strategies. Thus, four categories (time management, help seeking, effort regulation, and metacognitive strategies) would define metacognitive and resource management. Likewise, four other categories (rehearsal strategies, elaboration strategies, organization strategies, and critical thinking strategies) would adequately define the cognitive section (Zimmmerman, 1998). Table one depicts the correlation matrix among the eight categories of self regulated learning strategies. All correlations are significant at $p<.01$. Furthermore, Eigen values are in a decreasing order (5.743- .702- .436- .323-.263-.225-.181- .129). An eigen value is the variance of the factor. That is, the first factor accounts for the highest amount of variance, the second factor accounts for the second highest amount of variance, and so on. As such, quickly decreasing eigen values suggest that the eight factors hypothesized in this model provide a reasonable interpretation of the data.

The researchers used the AMOS Graphics to evaluate how well the data fit the model. Since in Huang's (2008) study the two latent variables i.e., metacognitive and self regulation strategies on the one hand and cognitive strategies on the other are correlated, the researchers did the same in this study. AMOS text output for the parameter summary and selected goodness-of-fit statistics indicated that there were 17 parameters to be estimated. Using Bentler and Chou's (1987) rule of thumb for calculating sample size, the upper bound will be $10 \times 17=170$, and the lower bound will be $5 \times 17=85$; the sample sizes for these examples within the acceptable range, indicating high statistical power.

\subsubsection{Model evaluation}

There are three categories of fit indices in structural equation modeling. The first group is called absolute fit indices. They do not use an alternative model as a base for comparison. Rather, they are derived from the fit of the obtained and implied covariance matrices. GFA (Goodness of Fit), AGFI (Adjusted Goodness of Fit) and RMSEA (Root Mean Square Error of Approximation) are all absolute indices. The second group is called relative (incremental) fit indices. They compare values for the model tested with the null model.NFI (Normed Fit Index) and NNFI (Non-Normed Fit Index) are relative indices. The third group is called non-centrality-based Indices. They are calculated by subtracting the degree of freedom of the model from the chi-square after adjusting for sample size. It has been suggested that researchers should report at least two indices from each category.

\subsubsection{Sample one}

The overall $\mathrm{ch}^{2 / \mathrm{df}}$ value for EFL sample with19 degrees of freedom is 1.148 , which is well below the recommended level of 3, indicating an acceptable fit. Other fit indices (GFI $=.90, \mathrm{AGFI}=.92$, and RMSEA $=.05)$ also suggest that the two-factor CFA model of MSLQ is a good fit. The AMOS text output for the maximum likelihood parameter estimates for the two-factor CFA model is presented in Table two. As can be observed the factor loadings for the two factors are all significant at $p<.05$ level since they are greater than the critical ratios (CR) of 1.96.

\subsubsection{Sample two}

We also examined the factor structure of the learning strategies module of MSLQ among a group of computer science students. As shown in tables 9 all the correlations among the variables were significant at $p<.01$. The model representing the scale yielded a good representation of the data $\left(\mathrm{Ch}^{2 / \mathrm{df}}=.837\right.$. GFA $=.95$, AGFI $=.90$, and RMSEA $=.000$ ), indicating acceptable goodness-of-fit indices. The results are consistent with the findings from the EFL group. Eigen values are decreasing in order (5.369- .709-.558-.368- .326-.263-.218 .189). This indicates that a two factor model is a reasonable interpretation of the data. Tables $9-16$ represent the relevant data.

\subsection{Multiple-group Factor Analysis}

The unconstrained and constrained models were fitted to the data. The unconstrained model assumed that the factor loadings varied across the two groups. The results indicated lack of fit, $\chi 2=179.2, p<.01$, AGFI $=.91$, $\mathrm{RMSEA}=.08, \mathrm{RMR}=.18$. The constrained model assumed that the factor loadings were almost the same across the two groups. The results indicated good fit to the data, $\chi 2=18.8, \mathrm{p}=.092$, AGFI $=.98$, RMSEA $=.04, \mathrm{RMR}=.03$. To test whether the parameters were the same across the eight subscales, the difference between the chi square values of the two models was computed. No significant differences were found between the two groups, $\chi 2=9.9$, $\mathrm{p}=.13$. The difference between the chi square statistics for this model and the model where all factor loadings can vary across the eight subscales was significant $\chi 2=170.3, \mathrm{p}<.01$.

\section{Conclusion}

The aim of this study was to see whether the MSLQ could be used to measure self regulated learning strategies employed by Iranian EFL students. Until now the MSLQ has been mainly used for general education in academic settings. The study was based on the assumption that self regulated learning strategies are not limited to the context of general education. Rather, they are fairly stable dispositions that can be applied to the context of EFL learning at the college level as well. This assumption is based on findings recently reported by Huang (2008). For this purpose, 
a translated version of the MSLQ was administered to a group of Iranian EFL students as well as a group of Iranian computer science students. The data were analyzed by confirmatory factor analysis to see whether the factor structure of the MSLQ was (a) the same across EFL and computer science groups and (b) whether the factor structure of both groups was in congruent with theoretical predictions. The results show a good fit between the data and theory and between the two groups. That is, while all factor loadings in both groups are significant, no significant differences were found between factor loadings between the two groups. They, therefore, could be assumed to measure aspects of the latent variables, pointing to construct applicability of the scale to both contexts i.e., EFL and general education. Moreover, Eigen Values are decreasing in both groups, indicating internal consistency. Finally, while the findings do confirm that the factor structure of the MSLQ is not significantly different between EFL and general education courses, the differences in the strengths of correlations between the MSLQ scores in the EFL group and the computer science group suggest that this scale is context sensitive. That is to say, this instrument is sensitive to the demands and constraints that each major puts upon the application of different strategies.

With respect to practical implications of the study, The MSLQ can be used as an alternative to the existing measures such as the strategy inventory of language learning (SILL) (Oxford, 2002) specially in factor analytic research, where the existence of latent constructs measured by manifest indicators is assumed. The MSLQ can also be a valuable tool for researchers doing research across discipline boundaries.

\subsection{Limitations of the Study}

The current study has a number of limitations. First, generalizations from this study might be limited because the participants were only undergraduate college students in just two majors. Second, the method of analysis is only quantitative, a qualitative supplement as a method of triangulation is needed to augment arguments made in this article.

\section{References}

Bentler, P. M. (1990). Comparative fit indexes in structural models. Psychological Bulletin, 107(2), 237-246. http://dx.doi.org/10.1037\%2F0033-2909.107.2.238

Bentler, P. M., \& Chou, C. (1987). Practical issues in structural modeling. Sociological Methods \& Research, 16 (1), 78-117. http://dx.doi.org/10.1177\%2F0049124187016001004

Byrne, B. M. (2001) Structural Equation Modeling with AMOS - Basic concepts, applications, and programming. Laurence Erlbaum Associates: Mahwah, New Jersey.

Ennis, C. (1991). Discrete thinking skills in two teaches' physical education classes. The Elementary School Journal. 91(5), 473-486. http://dx.doi.org/10.1086\%2F461670

Huang. S. (2008). Assessing motivation and learning strategies using the motivated strategies for learning questionnaire in a foreign language learning context. Social Behavior and Personality, 36 (4), 529-534. http://dx.doi.org/10.2224\%2Fsbp.2008.36.4.529

Oxford, R. L. (1990). Language learning strategies: What every teacher should know. New York: Newbury House/Harper \& Row.

Pintrich, P. R. (2000). The role of goal orientation in self-regulated learning. In M. Boekaerts, P. R. Pintrich, \& M. Zeidner (Eds.), Handbook of self regulation (pp. 452-502). New York: Academic Press.

Pintrich, P. R., Smith, D. A., Garcia, T., \& McKeachie, W. J. (1991). A Manual for the use of the Motivated Strategies for Learning Questionnaire (MSLQ). Ann Arbor, MI: The University of Michigan.

Schunk, D. H., \& Ertmer, P. A. (2000). Self-regulation and academic learning: Self-efficacy enhancing interventions. In M. Boekaerts, P. R. Pintrich, \& M. Zeidner (Eds.), Handbook of self-regulation (pp. 631-650). New York: Academic Press.

Swalander, L., \& Taube, K. (2007). Influences of family based prerequisites, reading attitude and self-regulation on reading ability. Contemporary Educational Psychology, 206-230. http://dx.doi.org/10.1016\%2Fj.cedpsych.2006.01.002

Stoffa, R., Kush, J. C., \& Heo. M. (2011). Using motivated strategies for learning questionnaire and strategy inventory for language learning in assessing motivation and learning strategies of generation 1.5 Korean immigrant students. Education Research International. [Online] Available: http://www.Hindawi.com/journals/edu/2011/491276/ (January $2^{\text {nd }}, 2011$ ), http://dx.doi.org/10.1155\%2F2011\%2F491276 
Tan, P. (2010). Towards a culturally sensitive and deeper understanding of "rote learning" and memorization of adult learners. Journal of Studies in International Education. [Online] Available: http://jsi.sagepub.com/content/early/html (March $8^{\text {th }}, 2011$ ), http://dx.doi.org/1028315309357940

Ten Dam, G., \& Volman, M. (2004). Critical thinking as a citizen competence: teaching strategies. Learning and Instruction, 14(3), 359-379

Tseng, W., Dörnyei, Z., \& Dierking, D. (2006). A new approach to assessing strategic learning: The case of self regulation in vocabulary acquisition. Applied Linguistics, 27 (1), 78-102. http://dx.doi.org/10.1016\%2Fj.learninstruc.2004.01.005

Warr, P., \& Downing, J. (2000). Learning strategies, learning anxiety, and knowledge acquisition. British journal of Psychology, 91, 311-334. http://dx.doi.org/10.1348\%2F000712600161853

Winne, P. H. (1995). Inherent details in self-regulated learning. Educational Psychologist. 30 (9), 173-188. http://dx.doi.org/10.1006\%2Fceps.1997.0919

Zimmerman, B. J., \& Risemberg, R. (1997). Becoming a self-regulated writer: A social cognitive perspective. Contemporary Educational Psychology, 22 (1), 73-101. http://dx.doi.org/10.1006\%2Fceps.1997.0919

Table 1. Intercorrelations among self regulated learning strategies among EFL students

\begin{tabular}{lcccccccc}
\hline & RS & ES & OS & CT & ER & HS & TM & MS \\
\hline RS & 1.000 & & & & & & & \\
ES & .710 & 1.000 & & & & & & \\
OS & .682 & .669 & 1.000 & & & & & \\
CT & .708 & .736 & .655 & 1.000 & & & & \\
ER & .734 & .690 & .732 & .712 & 1.000 & & & \\
HS & .610 & .642 & .727 & .722 & .728 & 1.000 & & \\
TM & .525 & .655 & .682 & .647 & .665 & .846 & 1.000 & \\
MS & .491 & .583 & .588 & .734 & .597 & .760 & .715 & 1.000 \\
\hline
\end{tabular}

Note: $\mathrm{RS}=$ Rehearsal strategies, $\mathrm{ES}=$ Elaboration strategies, $\mathrm{OS}=$ Organization strategies, $\mathrm{CT}=$ Critical thinking strategies, ER= Elaboration strategies, HS=Help seeking strategies, TM= Time management strategies, MS = Metacognitive strategies 
Table 2. AMOS Output: Maximum Likelihood Estimates for structural paths for MSLQ in context of foreign language learning

\begin{tabular}{lccccc}
\hline & Estimate & S.E. & C. R. & P & Label \\
MS (MR) & 1.000 & & & & \\
TM (MR) & .660 & .083 & 7.954 & $<.01$ & Par - 1 \\
ER (MR) & .874 & .101 & 8.667 & $<.01$ & Par - 2 \\
HS (MR) & 1.000 & & & & \\
RS (CS) & .960 & .114 & 8.425 & $<.01$ & Par - 3 \\
ES (CS) & .788 & .092 & 8.590 & $<.01$ & Par - 4 \\
OS (CS) & .614 & .076 & 8.024 & $<.01$ & Par - 5 \\
CT (CS) & .703 & .082 & 8.570 & $<.01$ & Par - 6
\end{tabular}

Note: RS=Rehearsal strategies, $\mathrm{ES}=$ Elaboration strategies, $\mathrm{OS}=$ Organization strategies, $\mathrm{CT}=$ Critical thinking strategies, $\mathrm{CS}=$ Cognitive strategies, $\mathrm{ER}=$ Elaboration strategies, $\mathrm{HS}=$ Help seeking strategies, $\mathrm{MR}=$ Metacognitive and resource management strategies, $\mathrm{TM}=$ Time management strategies, $\mathrm{MS}=$ Metacognitive strategies

Table 3. Two way relateship between the latent variables

\begin{tabular}{cccccc}
\hline & Estimate & S.E. & C. R. & p & Label \\
\hline MR CS & 1776.717 & 419.674 & 4.234 & $<.01$ & Par-7 \\
\hline
\end{tabular}

Note: $\mathrm{MR}=$ Metacognitive and resource management strategies, $\mathrm{CS}=$ Cognitive strategies

Table 4. $\mathrm{Ch}^{2}$ statistics

\begin{tabular}{lllll}
\hline \multicolumn{1}{c}{ Model } & NPAR & \multicolumn{2}{l}{ CMIN DF } & P CMIN/DF \\
Default model & 17 & 21.820 & 19.293 & 1.148 \\
Saturated model & 36 & .000 & 0 & \\
Independence model & 8 & 55.945 & 28.001 & 1.998 \\
Zero model & 0 & 240.000 & 36.000 & 6.667 \\
\hline mber of parameters, CMIN/DF=chi ${ }^{2 / d f}$, & P CMIN/DF =Probability of CMIN/DF
\end{tabular}

Table 5. Absolute goodness-of-fit indices

\begin{tabular}{lllll}
\hline \multicolumn{1}{c}{ Model } & RMR & GFI & AGFI & PGFI \\
Default model & 128.288 & .909 & .828 & .480 \\
Saturated model & .000 & 1.000 & & \\
Independence model & 1527.515 & .767 & .700 & .596 \\
Zero model & 1683.915 & .000 & .000 & .000 \\
\hline
\end{tabular}

Note: PAR=Parameter, GFI= (Goodness-of-fit), AGFI(Adjusted goodness-of-fit), PGFI (Parsimonious goodness-of-fit index) 
Table 6. Relative goodness-of-fit indices

\begin{tabular}{llllll}
\hline \multicolumn{1}{c}{ Model } & NFI & RFI & IFI & TLI & CFI \\
& Deltal & rhol & Deltal2 & rho2 & \\
& .610 & .425 & .924 & .851 & .899 \\
Default model & 1.000 & & 1.000 & & 1.000 \\
Saturated model & .000 & .000 & .000 & .000 & .000 \\
Independence model & .000
\end{tabular}

Note: $\mathrm{PAR}=$ Parameter, $\mathrm{NFI}=$ (Normed Fit Index) $), \mathrm{RFI}=$ Relative fit index, IFI=Incremental fit index.TLI= Tucker-Lewis index, $\mathrm{CFI}=$ Comparative fit index

Table 7. RMSEA index

\begin{tabular}{lllll}
\hline \multicolumn{1}{c}{ Model } & RMSEA & LO 90 & HI 90 & PCLOSE \\
Default model & .050 & .000 & .128 & .459 \\
Independence model & .129 & .079 & .178 & .009 \\
\hline
\end{tabular}

Note: RMSEA (Root mean squared error of approximation), LO=Low, HI=High, PCLOSE=Probability of close fit

Table 8. Hoelter's critical n

\begin{tabular}{lcc}
\hline \multicolumn{1}{c}{ Model } & HOELTER & HOELTER \\
& .05 & .01 \\
Default model & 83 & 100 \\
Independence model & 45 & 52 \\
Zero model & 13 & 15 \\
\hline
\end{tabular}

Table 9. Intercorrelations among self regulated learning strategies among computer science students

\begin{tabular}{lccllllll}
\hline & RS & ES & OS & CT & ER & HS & TM & MS \\
RS & 1.000 & & & & & & & \\
ES & .506 & 1.000 & & & & & & \\
OS & .653 & .560 & 1.000 & & & & & \\
CT & .727 & .643 & .690 & 1.000 & & & & \\
ER & .709 & .614 & .739 & .785 & 1.000 & & & \\
HS & .628 & .444 & .561 & .631 & .620 & 1.000 & & \\
TM & .515 & .576 & .557 & .658 & .694 & .661 & 1.000 & \\
MS & .598 & .421 & .518 & .653 & .660 & .709 & .667 & 1.000 \\
\hline
\end{tabular}

Note: $\mathrm{RS}=$ Rehearsal strategies, $\mathrm{ES}=$ Elaboration strategies, $\mathrm{OS}=$ Organization strategies, $\mathrm{CT}=$ Critical thinking strategies, $\mathrm{ER}=$ Elaboration strategies, $\mathrm{HS}=$ help seeking strategies, $\mathrm{TM}=$ Time management strategies, $\mathrm{MS}=$ metacognitive strategies 
Table 10. AMOS Output: Maximum Likelihood Estimates for structural paths for MSLQ among computer science students

\begin{tabular}{lccccc}
\hline & Estimate & S.E. & C. R. & P & Label \\
\hline MS (MR) & 1.000 & & & & \\
TM (MR) & .576 & .070 & 8.254 & $<.01$ & Par -1 \\
ER (MR) & .672 & .077 & 8.776 & $<.01$ & Par - \\
HS (MR) & 1.000 & & & & \\
RS (CS) & 1.015 & .089 & 11.369 & $<.01$ & Par - 3 \\
ES (CS) & .850 & .087 & 9.800 & $<.01$ & Par - 4 \\
OS (CS) & .494 & .068 & 7.282 & $<.01$ & Par - 5 \\
CT (CS) & .729 & .077 & 9.445 & $<.01$ & Par - 6 \\
\hline
\end{tabular}

Note: $\mathrm{RS}=$ Rehearsal strategies, $\mathrm{ES}=$ Elaboration strategies, $\mathrm{OS}=$ Organization strategies, $\mathrm{CT}=$ Critical thinking strategies, $\mathrm{CS}=$ Cognitive strategies, $\mathrm{ER}=$ Elaboration strategies, $\mathrm{HS}=$ help seeking strategies, $\mathrm{TM}$ Time management strategies, $\mathrm{MS}=$ metaognitive strategies, $\mathrm{MR}=$ Metacognitive and resource management strategies, $\mathrm{CS}=\mathrm{Cognitive}$ strategies, $\mathrm{S} . \mathrm{E}=$ standard estimate, $\mathrm{C} . \mathrm{R}=$ Critical ratio, $\mathrm{P}=$ Probability

Table 9. Two way prelateship between the latent variables

\begin{tabular}{cccccc}
\hline & Estimate & S.E. & C. R. & p & Label \\
\hline MR CS & 1649.880 & 335.428 & 4.919 & $<.01$ & Par-7 \\
\hline
\end{tabular}

Note: $\mathrm{MR}=$ Metacognitive and resource management strategies, $\mathrm{CS}=$ Cognitive strategies

Table 10. $\mathrm{Ch}^{2}$ statistics

\begin{tabular}{lcccc}
\hline \multicolumn{1}{c}{ Model } & NPAR & \multicolumn{1}{c}{ CMIN DF } & P CMIN/DF \\
Default model & 17 & 15.910 & 19.663 & .837 \\
Saturated model & 36 & .000 & 0 & \\
Independence model & 8 & 62.725 & 28.000 & 2.240 \\
Zero model & 0 & 316.000 & 36.000 & 8.778 \\
\hline
\end{tabular}

Note: $N P A R=$ Number of parameters, $\mathrm{CMIN} / \mathrm{DF}=\mathrm{chi}^{2 / \mathrm{df}}, \mathrm{P} C \mathrm{CMIN} / \mathrm{DF}=$ Probability of CMIN/DF

Table 13. Absolute goodness-of-fit indices

\begin{tabular}{lcccc}
\hline \multicolumn{1}{c}{ Model } & RMR & GFI & AGFI & PGFI \\
Default model & 60.000 & .950 & .905 & .501 \\
Saturated model & .000 & 1.000 & & \\
Independence model & 1343.404 & .802 & .745 & .623 \\
Zero model & 1504.922 & .000 & .000 & .000
\end{tabular}

Note: $\mathrm{PAR}=$ Parameter, GFI $=$ Goodness-of-fit, $\mathrm{AGFI}=$ Adjusted goodness-of-fit, $\mathrm{PGFI}=$ Parsimonious goodness of-fit index 
Table 14. Relative goodness-of-fit indices

\begin{tabular}{lccccc}
\hline \multicolumn{1}{c}{ Model } & NFI & RFI & IFI & TLI & CFI \\
& Deltal & rhol & Deltal2 & rho2 & \\
Default model & .746 & .626 & 1.071 & 1.131 & 1.000 \\
Saturated model & 1.000 & & 1.000 & & 1.000 \\
Independence model & .000 & .000 & .000 & .000 & .000
\end{tabular}

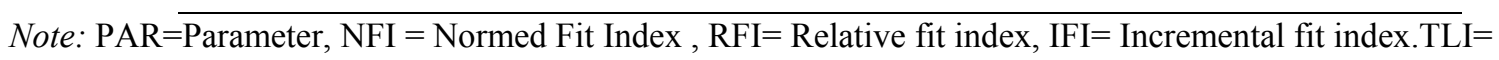
Tucker-Lewis index, CFI= Comparative fit index

Table 15. RMSEA index

\begin{tabular}{lcccc}
\hline \multicolumn{1}{c}{ Model } & RMSEA & LO 90 & HI 90 & PCLOSE \\
Default model & .000 & .000 & .081 & .827 \\
Independence model & .125 & .084 & .167 & .003
\end{tabular}

Note: RMSEA= Root mean squared error of approximation, $\mathrm{LO}=$ Low, HI= High, PCLOSE Probability of close fit

Table 16. Hoelter's critical $\mathrm{n}$

\begin{tabular}{lcc}
\hline \multicolumn{1}{c}{ Model } & HOELTER & HOELTER \\
& .05 & .01 \\
Default model & 150 & 180 \\
Independence model & 53 & 61 \\
Zero model & 13 & 15 \\
\hline
\end{tabular}

